\title{
Thin-Layer Chromatography of Metal Ions on Immobilized Chondroitin Sulfate Plate Prepared by Plasma Polymerization Technique
}

\author{
Kikuko Yoshimura, Takeshi Horita, ${ }^{*}$ and Keiichiro Hozumi* \\ Kansai Women's College, 3-11-1, Asahigaoka, Kashiwara-shi, Osaka 582, Japan \\ * Kyoto Pharmaceutical University, 5, Misasagi Nakauchi-cho, Yamashina-ku, \\ Kyoto 607, Japan
}

(Received August 7, 1995)

\begin{abstract}
Chondroitin sulfate (CS) as a sodium salt was impregnated within micropores of silica gel on a thin-layer chromatographic plate and coated by a thin film of plasma-polymerized propargyl alcohol (PPPA) for immobilization of CS macromolecules. Chromatographic behavior of cations such as $\mathrm{Co}^{2+}, \mathrm{Fe}^{2+}$, and $\mathrm{Cu}^{2+}$ was observed on the prepared thin-layer plate to explore ion-exchange functions from the acidic groups of CS. Affinity of the cations to the immobilized CS plate was enhanced with increasing CS impregnated in the silica gel, regardless of the kind of cation. Moreover, affinity was significantly altered by the mode of preliminary washing of the thin-layer plate, use of either aqueous or organic solvent, and adjusted pH of the solvent. The PPPA film itself indicated certain affinity to the cations, likely due to the oxygen-containing groups, e.g., - $\mathrm{OH}$, partly dissociable in the polymer matrix. The proposed technique suggests other new thin-layer chromatographic plates in which various ion-attractive or ion-exchange materials are immobilized.

KEY WORDS Plasma-Polymerized Propargyl Alcohol / Immobilization of Chondroitin Sulfate / Thin-Layer Chromatography of Cations /
\end{abstract}

A number of studies have been reported for materials which separate or distinguish various ions, because such function is applicable to broad fields of chemical processes or analytical chemistry. A recent paper reports an attempt to prepare ion-exchange membrane by plasma polymerization. ${ }^{1}$ The plasma polymerization technique has been also applied to thin-layer chromatography (TLC) and Yoshimura et al. reported successful results by coating a silica gel TLC plate with a plasma-polymer thin film prepared by use of propargyl alcohol (2propyn-1-ol, PA) as a monomer. ${ }^{2,3}$ Although the TLC plate coated with plasma-polymerized PA (PPPA) altered the migration rates of organic substances in comparison with non-coated TLC plate, the plasma technique was further applied to a TLC plate preliminarily impregnated with sodium salt of chondroitin sulfate (CS). ${ }^{4}$ The immobilization of $\mathrm{CS}$ was carried out by coating a CS-impregnated plate with PPPA in a similar manner to the preparation of an immobilized enzyme membrane by the PPPA-coating. ${ }^{5}$ Immobilized CS exhibited affinity to some biochemical substances, which is likely due to the resemblance of the molecular structure of CS or the acidic groups of the CS molecule.

This paper reports ion-exchange functions for metal cations using the immobilized CS plates. Different ways of preliminary washing of the plates were involved in this experiment for enhancement of the ion-exchange ability. Metal cations tested were $\mathrm{Co}^{2+}, \mathrm{Fe}^{2+}$, and $\mathrm{Cu}^{2+}$, since they are important biochemically and individual spots can be detected visibly.

The CS molecule shown in Figure 1 is constructed with alternately. repeated segments of D-glucuronic acid and $N$-acetylchondrosamine ( $N$-acetyl-2-amino-Dgalactose), the latter of which is esterified as 4-sulfate or 6-sulfate. ${ }^{6,7}$ Sulfonic and carboxyl groups are therefore considered ion-exchange sites within the CS molecule.

\section{EXPERIMENTAL}

\section{Materials}

Sodium CS (CS-Na) and acetone were supplied from Kanto Chemicals Inc. (Tokyo) and all the other reagents were from Nacalai Tesque Inc. (Kyoto). Quality of the reagents was guaranteed grade except that PA was an extrapure reagent. The TLC plate was purchased from Whatman Ltd. (United Kingdom) as a Silica GelPrecoated Plate (thickness of silica gel layer, $250 \mu \mathrm{m}$; back plate, aluminum).

\section{Preparation of Thin-Layer Plate}

The PPPA-coating of the TLC plate was carried out as described previously. ${ }^{4,8}$ The TLC plate $\left(5 \times 10 \mathrm{~cm}^{2}\right)$ was placed between a pair of parallel electrodes installed within the Plasma Deposition System Model BP-1 (Samco International Lab. Inc., Kyoto), and the plasma chamber was evacuated with High Vacuum Pump E2M-12 (3001 $\mathrm{min}^{-1}$, Edwards Inc., United Kingdom). The rate of evacuation was controlled by a throttle valve, monitoring by a Thermocouple Vacuum Gauge (Thermocouple 1 and Gauge Head TC1, Edwards Inc.), so as to hold the pressure at the desired level. After

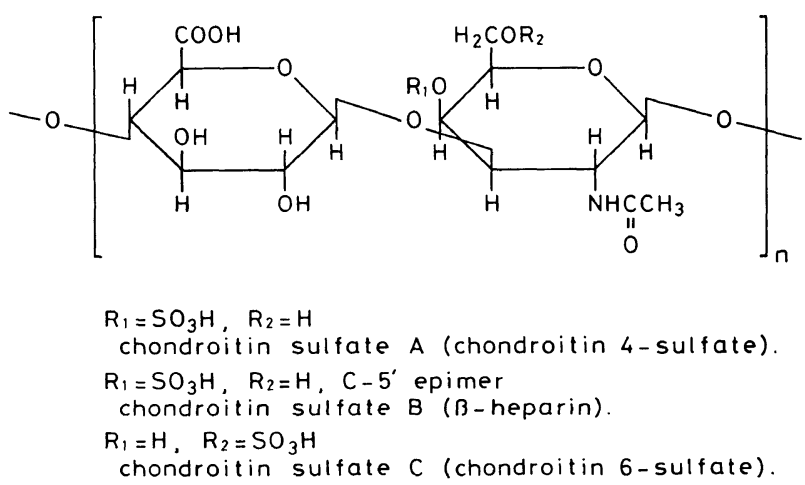

Figure 1. Chemical structure of chondroitin sulfate (CS). 
preliminary evacuation, vapor of PA was slowly transported from a glass reservoir into the plasma chamber through a thin metal tube.

At approximately 0.1 Torr, plasma discharge was initiated and sustained by a radio-frequency electric power $(13.56 \mathrm{MHz})$ of $5 \mathrm{~W}$, while a thin film of PPPA was uniformly deposited on the TLC plate. Film thickness on the TLC plate could be controlled by the time of deposition. The CS-immobilized TLC plate was prepared by soaking a new TLC plate in aqueous CS-Na solution, air-drying overnight, and plasma processing as above.

\section{Thin-Layer Chromatography}

Chromatography was carried out using the intact plate, PPPA-coated plate, and immobilized CS plate. Preliminary washing was applied to the plate with distilled water or $3 \% \mathrm{HCl}$ solution. Time for washing was regulated within $1 \mathrm{~min}$ for either case, but $1 \mathrm{~min}$ more with distilled water was added to the latter case for neutralization. After drying at room temperature, sample solutions of $2 \mu \mathrm{l}$ were spotted on the TLC plate. Sample solutions of $\mathrm{Co}^{2+}, \mathrm{Fe}^{2+}$, and $\mathrm{Cu}^{2+}$ were prepared by dissolving $\mathrm{CoCl}_{2} \cdot 6 \mathrm{H}_{2} \mathrm{O}, \mathrm{FeCl}_{2}$, and $\mathrm{CuCl}_{2}$. $2 \mathrm{H}_{2} \mathrm{O}$ in water at $5 \mathrm{~g}^{-1}$. Development of the sample ions was continued until the solvent front reached $8 \mathrm{~cm}$ from the origin.

Various developing solvents were considered, referring to solvent mixtures for ion-exchange chromatography and volatile buffer solutions for zone electrophoresis. The solvent mixtures were prepared as follows: (a) $0.1 \mathrm{M}$ ethylenediamine/0.2 $\mathrm{M}$ tartaric acid, (pH 4); (b) $0.5 \mathrm{M}$ nitric acid $/ 10 \%$ pyridine in acetone/water $(4: 1),(\mathrm{pH} 6)$; (c) pyridine/acetic acid/water, $(\mathrm{pH} 3.1, \mathrm{pH} 4.7, \mathrm{pH} 6.5)$; (d) $0.5 \mathrm{M}$ nitric acid in acetone/water $(4: 1),(\mathrm{pH} 1)$. The spots of $\mathrm{Co}^{2+}, \mathrm{Fe}^{2+}$, and $\mathrm{Cu}^{2+}$ were detected by coloration after spraying saturated acetone solutions of ammonium thiocyanate, $o$-phenanthroline (1,10-phenanthroline), and cuproine (2,2'-biquinoline), respectively. $R_{\mathrm{f}}$ of the individual spot was measured and relative ratios of $R_{\mathrm{f}}$ calculated as "Processed plate/Intact plate" were evaluated.

\section{RESULTS AND DISCUSSION}

\section{Time for Coating}

Since CS still holds ion-exchange functions after irradiation of PA plasma and PPPA film exhibits certain interactions with $\mathrm{H}^{+}, 9$ the CS-impregnated and/or the PPPA-coated plates were naturally assumed to interact with cations by the same mechanism as ion-exchange chromatography. In the previous study, ${ }^{4}$ the plasma processed plates were simply washed with developing solvent to remove weakly bound PPPA and CS on the TLC plate. However, in this work, a variety of washing processes was applied to improve ion-exchange ability.

An appropriate time for coating of the PPPA film on the TLC plate was selected because the film thickness is an important factor in interactions between sample cations and the surface of the TLC plate. A comparative study was made with a number of TLC plates processed by various conditions. The results are tabulated in Table I.
Table I. Effects of PPPA-coating and impregnation of CS on $R_{\mathrm{f}}$ of cations

(A) $R_{\mathrm{f}}$-Value

\begin{tabular}{cccccc}
\hline & \multicolumn{5}{c}{$R_{\mathrm{f}}$ value (SD) } \\
\cline { 2 - 5 } Cation & $I^{\mathrm{a}}$ & $P_{10}{ }^{\mathrm{b}}$ & $P_{30}{ }^{\mathrm{c}}$ & $C^{\mathrm{d}}$ & $C+P^{\mathrm{c}}$ \\
\hline \multirow{2}{*}{$\mathrm{Co}^{2+}$} & 0.85 & 0.85 & 0.88 & 0.51 & 0.44 \\
& $(0.04)$ & $(0.06)$ & $(0.05)$ & $(0.06)$ & $(0.09)$ \\
$\mathrm{Fe}^{2+}$ & 0.86 & 0.81 & 0.84 & 0.60 & 0.54 \\
& $(0.02)$ & $(0.03)$ & $(0.02)$ & $(0.07)$ & $(0.03)$ \\
$\mathrm{Cu}^{2+}$ & 0.80 & 0.88 & 0.87 & 0.40 & 0.56 \\
& $(0.06)$ & $(0.04)$ & $(0.01)$ & $(0.02)$ & $(0.09)$ \\
\hline
\end{tabular}

(B) Ratios of $R_{\mathrm{f}}$

\begin{tabular}{lcccc} 
& \multicolumn{4}{c}{ Ratio of $R_{\mathrm{f}}$ value } \\
& $P_{10}{ }^{\mathrm{b}} / I^{\mathrm{a}}$ & $P_{30}{ }^{\mathrm{c}} / I$ & $C^{\mathrm{d}} / I$ & $C+P^{\mathrm{e}} / I$ \\
\hline $\mathrm{Co}^{2+}$ & 1.00 & 1.04 & 0.59 & 0.51 \\
$\mathrm{Fe}^{2+}$ & 0.94 & 0.98 & 0.70 & 0.63 \\
$\mathrm{Cu}^{2+}$ & 1.10 & 1.09 & 0.50 & 0.70 \\
\hline
\end{tabular}

Silica gel TLC plate: ${ }^{\mathrm{a}} I$, Intact. ${ }^{\mathrm{b}} P_{10}$, PPPA-coated $(10 \mathrm{~min})$. ${ }^{\mathrm{c}} P_{30}$, PPPA-coated $(30 \mathrm{~min}) .{ }^{\mathrm{d}} \mathrm{C}$, Impregnated with $\mathrm{CS}-\mathrm{Na}(3 \%)$. ${ }^{\mathrm{c}} \mathrm{C}+\mathrm{P}$, Impregnated with $\mathrm{CS}-\mathrm{Na}(3 \%)$ and PPPA-coated $(10$ or $20 \mathrm{~min}$ )

Developing solvent, $0.1 \mathrm{M}$ ethylenediamine $/ 0.2 \mathrm{M}$ tartaric acid. Washing, water (1 min). Number of measurement, 3-6.

Mean $R_{\mathrm{f}}$ of the each cation is indicated in column (A) with standard deviation $(n=3-6)$ and the ratio of $R_{\mathrm{f}}$ is in column (B). The data was obtained from five types of test plates, namely, the intact TLC plate, TLC plate coated with PPPA for $10 \mathrm{~min}$, the same plate coated for $30 \mathrm{~min}$, CS-impregnated plate using $3 \%$ $\mathrm{CS}-\mathrm{Na}$ solution, and finally the CS-impregnated and PPPA-coated plate. The test plates were washed with water for $1 \mathrm{~min}$ and air-dried before chromatography with a mixed solvent of $0.1 \mathrm{M}$ ethylenediamine $/ 0.2 \mathrm{M}$ tartaric acid.

In terms of $R_{\mathrm{f}}$, the migration rates of the cations on the simple PPPA-coated plates were almost independent of time for coating in spite of large differences of film thickness. Since the deposition rate of PPPA was determined as roughly $450 \AA \mathrm{min}^{-1}$, the thickness of the polymer film would grow up to $4500 \AA$ or $13500 \AA$ during a deposition time of $10 \mathrm{~min}$ or $30 \mathrm{~min}$, respectively. Elliptical extension of sample spots along the direction of solvent flow was reduced on the PPPA-coated plates in comparison with intact TLC plate. Since the elliptical extension of a sample spot appears when solvent flow is comparably fast with respect to adsorption force, ${ }^{10}$ the PPPA-coating should bring about a proper balance between the rate of development and adsorption force, hence reducing the elliptical extension of the spots. Relatively higher $R_{\mathrm{f}}$ was observed with $\mathrm{Co}^{2+}$ and $\mathrm{Cu}^{2+}$, while lower values were obtained with $\mathrm{Fe}^{2+}$. This implies certain differences of interactions between the metal cations and PPPA film. The PPPA network contains abundant oxygen atoms as hydroxyl, carbonyl and etheric groups. ${ }^{8}$ Partial dissociation of the first group acts as a cation exchange site and the other groups capture cations due to weak negativity. It is therefore understandable that the different cations showed individual interactions with the three oxygen groups within 
the PPPA network.

In the case of the CS-impregnated TLC plate, significant decrease of $R_{\mathrm{f}}$ of three cations was observed, although CS retained in the TLC plate was simply adsorbed on microstructure of silica gel. The physicochemical state of the CS in the TLC plate has not been studied in detail, and $\mathrm{CS}-\mathrm{Na}$ molecules seem to be trapped fairly well in the micropores of silica gel possibly bound by intermolecular forces between the CS-Na and the silanol groups of silica gel. Noticeable cation-capture ability of CS was thus evident. The sample spots, however, showed some distortion and tailing. Such spots unsuitable for TLC suggest that the CS adsorbing the cations is gradually carried by the developing solvent.

When the CS-impregnated TLC plate was further coated with PPPA, the distortion and tailing of the spots were much reduced and $R_{\mathrm{f}}$ were not affected by the time of PPPA-coating for either $10 \mathrm{~min}$ or $20 \mathrm{~min}$. Therefore, the CS-Na molecules adsorbed on the silica gel were immobilized by enclosure with the PPPA film and time needed for the immobilization should be $10 \mathrm{~min}$ or less.

The ratio of $R_{\mathrm{f}}$ tabulated in (B) indicates more clearly the effects from PPPA-coating and impregnation of CS on the migration rates of the cations. The plate processed with CS-impregnation and PPPA-coating lowered the ratio of $R_{\mathrm{f}}$ to $50-70 \%$ compared with the intact TLC plate. Although this would be due to the presence of CS, $\mathrm{Cu}^{2+}$ showed somewhat higher ratios of $R_{\mathrm{f}}$ probably because of weaker interactions with the PPPA film than other cations. It is concluded that the overall effect of CS-immobilization on cations was derived from both cation-CS and cation-PPPA interactions.

\section{Development with Aqueous Solvent}

Investigation was continued on cation-capture ability of the immobilized CS plate, whether it was dependent on the amount of CS impregnated and way of washing before the development. The developing solvent was an aqueous solution of $0.1 \mathrm{M}$ ethylenediamine $/ 0.2 \mathrm{M}$ tartaric acid. Figure 2 shows the results of different pretreatments, (A) without washing, (B) washing with water, and (C) washing with $3 \% \mathrm{HCl}$. The abscissa indicates the concentration of aqueous CS-Na solution used for impregnation within the TLC plate. The ordinate is employed for the ratio of $R_{\mathrm{f}}$ obtained by comparison with the intact TLC plate.

Regardless of the mode of preliminary washing, the ratio of $R_{\mathrm{f}}$ of any cation mostly decreased with increasing concentration of CS-Na solution $(0-10 \%)$ for impregnation. However, fairly characteristic curves drawn changed in dependent on the way of washing. Inconsistency of the curves of three cations, which was hardly recognized in the case of (A), became prominent in the case of (B) and more in the case of (C). It was clear that the preliminary washing with water removed low molecular species of PPPA and some CS-Na molecules due to incomplete immobilization. The washing with water seemed to promote partial desalination of CS-Na and conversion to CS form. Washing with $3 \%$ $\mathrm{HCl}$ considerably converted $\mathrm{CS}-\mathrm{Na}$ to free $\mathrm{CS}$, so that the evaluation of the cations-CS interactions should become more substantial.

Comparison of cases (B) and (C) showed large dif-
(A) Without washing

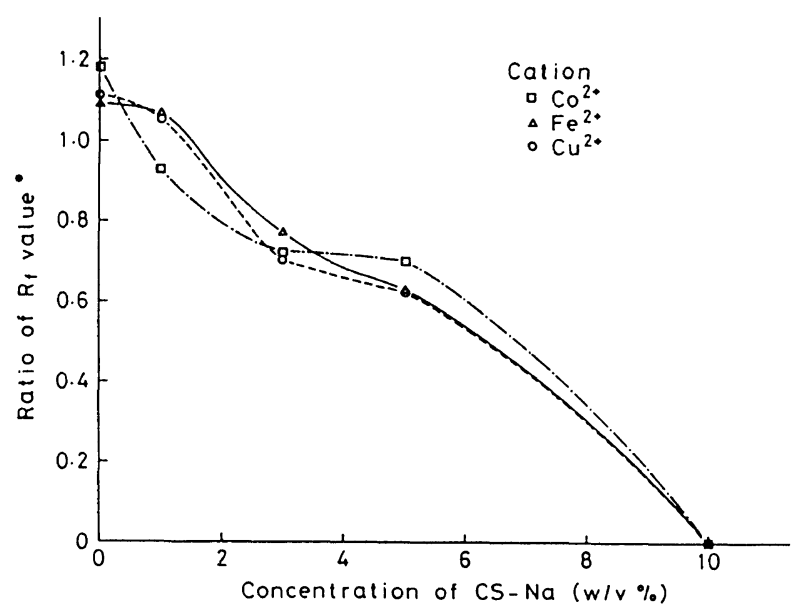

(B) Washing with water

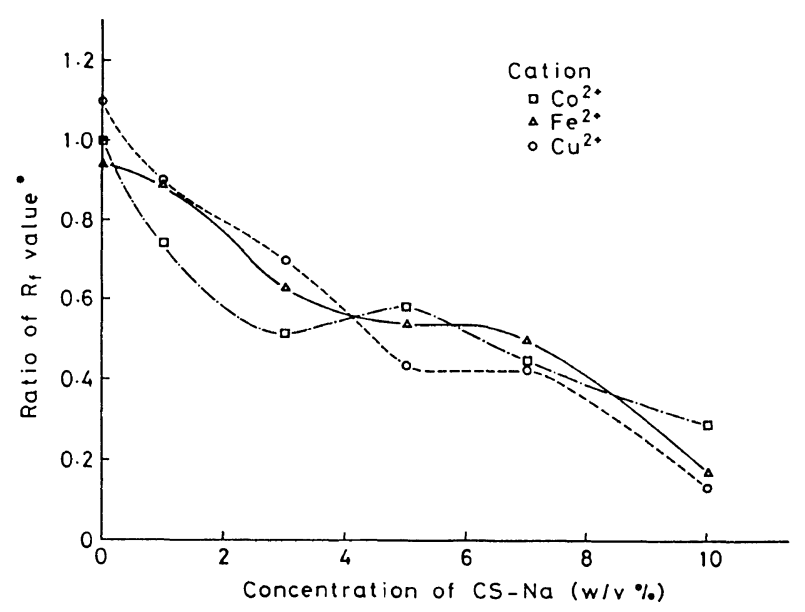

(C) Washing with $3 \% \mathrm{HCl}$

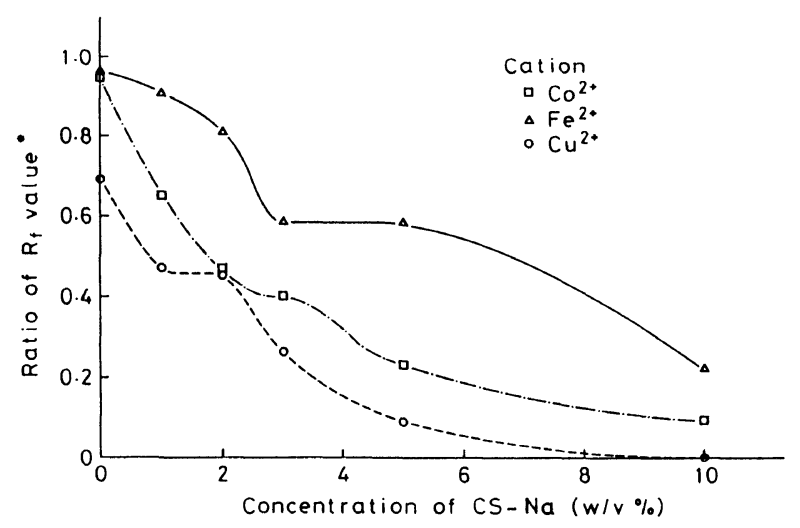

Figure 2. Effects of CS-immobilization on ratios of $R_{\mathrm{f}}$ of cations using aqueous developing solvent: substrate, silica gel TLC plate; developing solvent, $0.1 \mathrm{M}$ ethylenediamine $/ 0.2 \mathrm{M}$ tartaric acid. ${ }^{*} \mathrm{CS}$ Immobilized/Intact. (A) without washing; (B) washing with water; (C) washing with $3 \% \mathrm{HCl}$.

ferences of the ratios of $R_{\mathrm{f}}$ for $\mathrm{Co}^{2+}$ and $\mathrm{Cu}^{2+}$, while small changes with $\mathrm{Fe}^{2+}$. It is supposed that the ionexchange rate between $\mathrm{H}^{+}$and $\mathrm{Fe}^{2+}$ is not far from that between $\mathrm{Na}^{+}$and $\mathrm{Fe}^{2+}$ or that other complex surface interactions caused the above results.

Exceptionally different behavior of $\mathrm{Cu}^{2+}$ was observed when the plate was washed with $3 \% \mathrm{HCl}$. The TLC plate 
Table II. Time for development of cations using aqueous and organic solvents ${ }^{\mathrm{a}}$

\begin{tabular}{ccc}
\hline \multirow{2}{*}{$\begin{array}{c}\text { Concentration } \\
\text { of CS-Na }\end{array}$} & \multicolumn{2}{c}{ Time for development $/ \mathrm{h}$} \\
\cline { 2 - 3 } $\mathrm{w} / \mathrm{v} \%$ & $\begin{array}{c}0.1 \mathrm{M} \text { ethylenediamine } \\
/ 0.2 \mathrm{M} \text { tartaric acid }\end{array}$ & $\begin{array}{c}0.5 \mathrm{M} \mathrm{HNO}_{3} / 10 \% \text { pyridine } \\
\text { /acetone : water }(4: 1)\end{array}$ \\
\hline 0 & 0.5 & 0.5 \\
1 & 1.0 & 0.5 \\
3 & 2.0 & 0.5 \\
5 & 5.0 & 0.5 \\
10 & $\geqq 7.0$ & 0.5 \\
\hline
\end{tabular}

${ }^{\mathrm{a}}$ Distance of development, $8 \mathrm{~cm}$.

coated only with PPPA showed the ratio of $R_{\mathrm{f}}$ of 0.69 for $\mathrm{Cu}^{2+}$ when the plate was preliminarily washed with $3 \% \mathrm{HCl}$. Therefore, the characteristic behavior of the $\mathrm{Cu}^{2+}$ in the case of $(\mathrm{C})$ seems to result from two types of cation-capture ability from free CS and PPPA film after the acid treatment. This implies that PPPA itself may be utilized as cation-capture material after proper pretreatment.

\section{Developing Solvent and Time for Development}

Although the ion-capture ability of the immobilized CS plate is enhanced with increasing concentration of CS-Na solution utilized for impregnation of the TLC plate, the time necessary for development of the cations is markedly longer. Table II shows the time needed for development of $8 \mathrm{~cm}$ using aqueous and organic solvents.

Using $0.1 \mathrm{M}$ ethylenediamine $/ 0.2 \mathrm{M}$ tartaric acid aqueous solvent, the time for development varied from $30 \mathrm{~min}$ to $7 \mathrm{hrs}$ or more, owing to the concentration of $\mathrm{CS}-\mathrm{Na}$ for impregnation from 0 to $10 \%$. Such time for development was thought caused by gelation of CS where a large amount of water in the developing solvent was retained for the swelling of CS.

The organic solvent was therefore used. Acetonewater $(4: 1)$ mixed solvent was employed to make up $0.5 \mathrm{M}$ nitric acid $/ 10 \%$ pyridine solution. In contrast to the aqueous developing solvent, the organic solvent migrated on the immobilized CS plate at a constant speed $(30 \mathrm{~min} / 8 \mathrm{~cm})$ regardless of the amount of $\mathrm{CS}$ on the plate.

\section{Development with Organic Solvent}

The relationship between the concentration of CS-Na solution used for impregnation and ratio of $R_{\mathrm{f}}$ (CSImmobilized/Intact) was studied with the organic developing solvent in the same way as in the case of the aqueous solvent. The results are illustrated in Figure 3 , where (A) indicates the data obtained after the preliminary washing with water and (B) is with $3 \% \mathrm{HCl}$.

In the case of (A), all curves of three cations exhibited no decrease in the ratio of $R_{\mathrm{f}}$ with increasing CS-Na impregnated. Such behavior was noticeably different from the case using the aqueous developing solvent. However, the ratios of $R_{\mathrm{f}}$ for $\mathrm{Co}^{2+}$ and $\mathrm{Cu}^{2+}$ with the simply PPPA-coated (without CS) plate indicated similar values to that with the aqueous solvent, while $\mathrm{Fe}^{2+}$ showed an exceptionally low ratio of 0.4 to the intact TLC plate.
(A) Washing with water

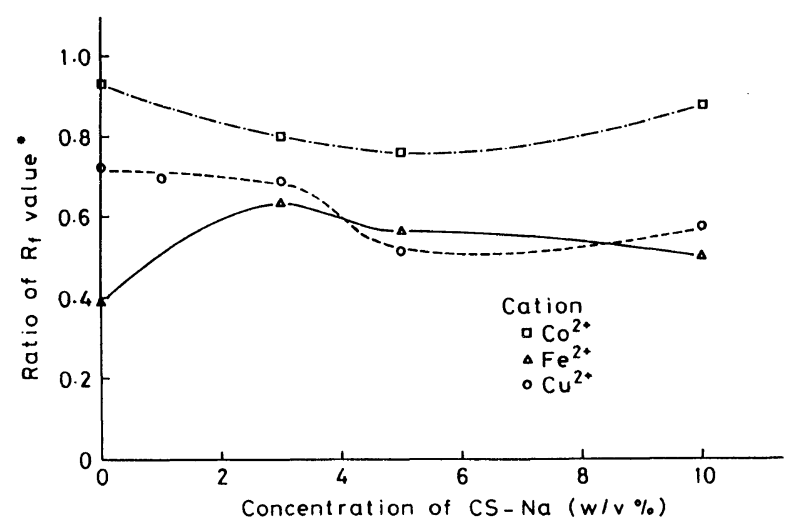

(B) Washing with $3 \%$ HCl

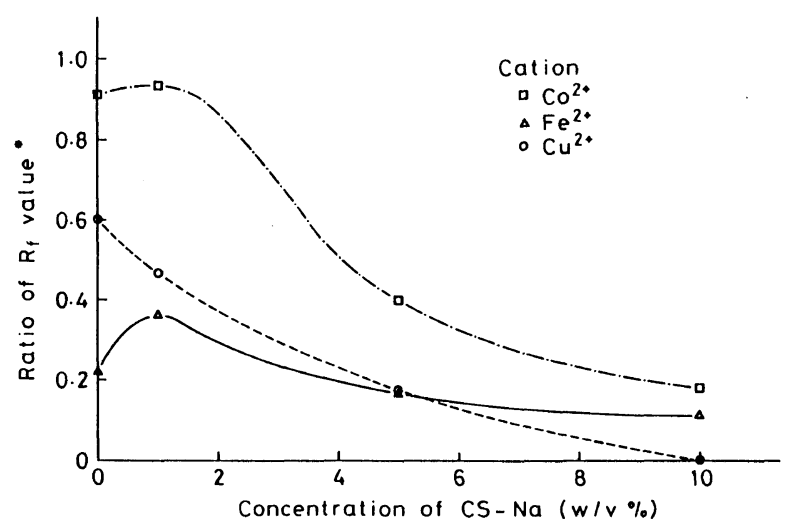

Figure 3. Effects of CS-immobilization on ratios of $R_{\mathrm{f}}$ of cations using organic developing solvent: substrate, silica gel TLC plate; developing solvent, $0.5 \mathrm{M} \mathrm{HNO}_{3} / 10 \%$ pyridine/acetone-water (4:1). *CS-Immobilized/Intact. (A) washing with water; (B) washing with 3\% $\mathrm{HCl}$.

The preliminary washing with $3 \% \mathrm{HCl}$ led to reduction in the ratio of $R_{\mathrm{f}}$ with increasing $\mathrm{CS}-\mathrm{Na}$ as shown in (B). These results suggest that development with organic solvent such as the case of (A) suppressed gelation and partial desalination of CS- $\mathrm{Na}$ impregnated. On the other hand, preliminary washing with $3 \% \mathrm{HCl}$ in such case as (B) produced much free CS within the PPPA matrix, so that cation-capture ability was enhanced with increasing CS-Na impregnated even if the development was carried out with organic solvent.

By detailed comparison of the affinity to the stationary phase, $\mathrm{Cu}^{2+}$ was more efficiently captured than $\mathrm{Co}^{2+}$ whenever developed with the organic solvent or on the processed plate preliminarily washed with $3 \% \mathrm{HCl}$. Great increase in affinity of $\mathrm{Fe}^{2+}$ was brought about by the organic solvent, and $\mathrm{Fe}^{2+}$ showed the strongest affinity after preliminary washing with $3 \% \mathrm{HCl}$ in all cases of the TLC plate simply coated with PPPA. This affinity of PPPA for $\mathrm{Fe}^{2+}$ should also contribute to the affinity between $\mathrm{Fe}^{2+}$ and the immobilized CS plate prepared by PPPA-coating, while the affinity of the plate for $\mathrm{Cu}^{2+}$ became comparable to and exceeded that for $\mathrm{Fe}^{2+}$ by increasing the amount of CS-Na impregnated. Overall, these results imply that the affinity of metal cations to the immobilized CS plate is derived not only from the acidic functional groups of CS but also from 


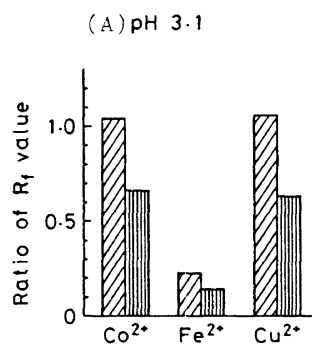

$$
\text { (B) } \mathrm{pH} 4.7
$$

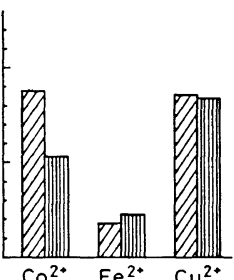

(C) $\mathrm{pH} 6.5$

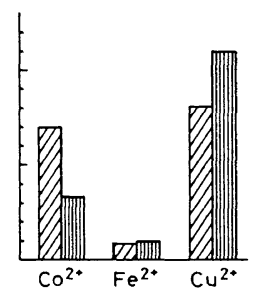

Figure 4. Effects of $\mathrm{pH}$ of developing solvent on $R_{\mathrm{f}}$ of cations: TLC plate, silica gel on aluminum foil; washing, water $(1 \mathrm{~min})$; developing solvent, pyridine/acetic acid/water. Ratio of $R_{\mathrm{f}}$-value: coated $(10 \mathrm{~min})] /[$ intact] $; \mathrm{dm}$, [impregnated with CS-Na $(3 \%)$ and PPPA-coated $(10 \mathrm{~min})] /[$ intact $]$.

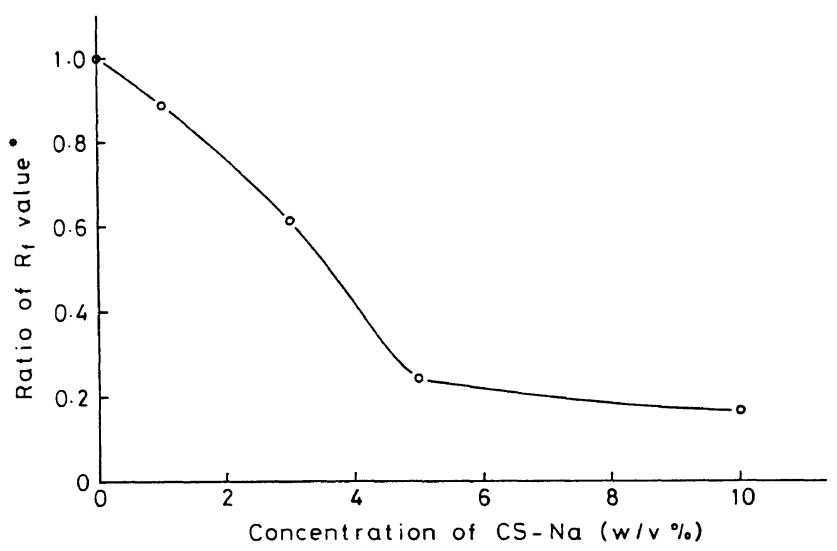

Figure 5. Effects of CS-immobilization on ratios of $R_{\mathrm{f}}$ of $\mathrm{Fe}^{2+}$ : substrate, silica gel TLC plate; developing solvent, $0.5 \mathrm{M} \mathrm{HNO}_{3} /$ acetone-water $(4: 1)$; washing, $3 \% \mathrm{HCl}$. ${ }^{*} \mathrm{CS}$-Immobilized/Intact.

the properties of PPPA.

\section{pH of Developing Solvent}

Generally, the chromatographic behavior of cations is dependent on $\mathrm{pH}$ of the eluent during ion-exchange chromatography. Considering the existence of ionexchange sites such as sulfonic and carboxylic groups in $\mathrm{CS}$, the $\mathrm{pH}$ of developing solvent should affect $R_{\mathrm{f}}$ of cations on the immobilized CS plate. This point was investigated with the immobilized CS plate and the simply PPPA-coated plate by changing $\mathrm{pH}$ of the developing solvent composed of pyridine/acetic acid/ water. The mixed solvent is "volatile buffer solution" excluding metal ions and the $\mathrm{pH}$ is adjusted by changing the compositions of pyridine and acetic acid over a wide range. The effect of $\mathrm{pH}$ on $R_{\mathrm{f}}$ was examined by comparison of the ratios of $R_{\mathrm{f}}$ (Processed/Intact). The results are shown in Figure 4 as a bargraph with data for $\mathrm{pH} 3.1,4.7$, and 6.5.

It was observed that the bargram for the PPPA-coated plate generally reduced ratio of $R_{\mathrm{f}}$ at higher $\mathrm{pH}$, suggesting ion-exchange ability of PPPA with cations. The immobilized CS plate prepared by impregnation of $3 \%$
CS-Na showed different results for the cations, probably due to competitive interactions between PPPA and $\mathrm{CS}$ which both were reactive to $\mathrm{pH}$.

As a comparative example, $\mathrm{Fe}^{2+}$ was developed on the immobilized CS plate with strongly acidic solvent and the data are shown in Figure 5. Solvent composition was $0.5 \mathrm{M}$ nitric acid/acetone-water (4:1) with an apparent $\mathrm{pH}$ of 1 . A wide range of ratio of $R_{\mathrm{f}}$ was obtained by changing the amount of CS on the TLC plate, and time for development was within $30 \mathrm{~min}$. Therefore, this TLC condition was judged to be favorable for development of $\mathrm{Fe}^{2+}$ in terms of the time needed for the development and the range of controllable $R_{\mathrm{f}}$ by reference to the results shown in Figures 2, 3, and Table II. The instance suggests that ratios of $R_{\mathrm{f}}$ for cations were largely altered by $\mathrm{pH}$ of the developing solvent on the processed TLC plate.

\section{CONCLUSIONS}

It may be concluded that the CS-immobilized TLC plate displays cation-capture ability largely affected by the presence of PPPA film, amount of CS immobilized, way of preliminary washing of the processed plate, and developing solvent adjusted at different $\mathrm{pH}$. PPPA film contributed not only to immobilization of CS but also to capture of metal cations. Cation-capture ability of the immobilized CS plate was derived from synthetic properties of PPPA film and CS immobilized. The plasma polymerization technique should be extensively applicable to the preparation of other chromatographic media or biochemical sensors.

\section{REFERENCES}

1. Z. Ogumi and Z. Takehara, Kagaku, 45 (3), 212 (1990).

2. K. Yoshimura, K. Hozumi, K. Kitamura, T. Kitade, and Y. Okamoto, Bunseki Kagaku, 35, 496 (1986).

3. K. Yoshimura, M. Ashida, Y. Nishimoto, A. Sakai, T. Kitade, K. Kitamura, and K. Hozumi, Bunseki Kagaku, 38, 443 (1989).

4. K. Yoshimura, A. Sakai, T. Horita, and K. Hozumi, Polym. J., 28, 284 (1996).

5. K. Yoshimura, T. Kitade, K. Kitamura, and K. Hozumi, Microchem. J., 43, 133 (1991).

6. M. Windholy, S. Budavari, R. F. Blumetti, and E. S. Otterbein, Ed., "The Merck Index," 10th ed, Merck \& Co., Inc., Rahway, N.J., 1983, p 314.

7. S. Shida, Representative Ed., "Kagaku Jiten (Dictionary of Chemistry)," Morikita Publishing Co., Tokyo, 1993, pp. 466, 813, and 1148 .

8. K. Yoshimura, T. Kitade, K. Kitamura, and K. Hozumi, J. Appl. Polym. Sci., 38, 1011 (1989).

9. T. Kitade, Y. Tanizaki, H. Yoneda, K. Kitamura, and K. Hozumi, Bunseki Kagaku, 39, 637 (1990).

10. Y. Izumi, M. Ogawa, S. Kato, J. Shiokawa, and T. Shiba, Ed., "Kikibunseki No Tebiki, Zohokaiteiban (Guidebook to Instrumental Analysis, Revised Edition)," Vol. 2, the 10th ed, Kagakudojin, Kyoto, 1993, pp. 37 and 53. 